\title{
Quality of Life of Chronic Kidney Disease Patients in the Republic of the Congo
}

\author{
Gael Honal Mahoungou ${ }^{1,2 *}$, Daniel Tony Eyeni Sinomono1,2, Yannick Dimi Nyanga ${ }^{2,3}$, \\ Tanee Fomum1, Steve Ondziel Opara2,3, Helena Botokoto Bothard1, Jean Lucien Mobengo1, \\ Richard Loumingou1,2, Blaise Iréné Atipo Ibara ${ }^{2,4}$
}

\footnotetext{
${ }^{1}$ Department of Nephrology, University Hospital of Brazzaville, Brazzaville, Republic of the Congo

${ }^{2}$ Faculty of Heath Sciences, University Marien Ngouabi, Brazzaville, Republic of the Congo

${ }^{3}$ Department of Urology, University Hospital of Brazzaville, Brazzaville, Republic of the Congo

${ }^{4}$ Department of Gastroenterology, University Hospital of Brazzaville, Brazzaville, Republic of the Congo

Email: *mahoungougael@yahoo.fr
}

How to cite this paper: Mahoungou, G.H., Sinomono, D.T.E., Nyanga, Y.D., Fomum, T., Opara, S.O., Bothard, H.B., Mobengo, J.L., Loumingou, R. and Ibara, B.I.A. (2021) Quality of Life of Chronic Kidney Disease Patients in the Republic of the Congo. Open Journal of Nephrology, 11, 495-505. https://doi.org/10.4236/ojneph.2021.114042

Received: November 14, 2021

Accepted: December 27, 2021

Published: December 30, 2021

Copyright $\odot 2021$ by author(s) and Scientific Research Publishing Inc. This work is licensed under the Creative Commons Attribution International License (CC BY 4.0).

http://creativecommons.org/licenses/by/4.0/

\begin{abstract}
Background: Chronic kidney disease could impair the quality of life of patients regardless of the stage of the disease. So far, there is no data on this subject in the Congolese population. The objective of this study was to assess the quality of life of patients with chronic kidney disease in Congo. Patients and methods: We conducted a cross-sectional, descriptive study of 91 patients followed in the department of nephrology and in dialysis centers in Brazzaville, Pointe-Noire and Oyo from July $1^{\text {st }}$ to November $30^{\text {th }}$, 2020, i.e. five months. We used the Kidney disease quality of life short form health survey score (KDQOL-SF 36) to assess the quality of life of patients and a questionnaire was used to determine socio-demographic, clinical and therapeutic features. Data analysis was done on SPSS 2.2 software. Result: The average age was $51.9 \pm 15$ years. The sex ratio $\mathrm{M} / \mathrm{F}$ was 2.03 . The average time of patient follow-up was 15 months; $90 \%$ of them had hypertension. The overall average score of specific dimensions was $52 \pm 18$; disease burden was the dimension most affected; that of the generic dimensions was $34 \pm 25$ with the limitation of physical activity dimension being the most affected. No patient had received psychological follow-up. Conclusion: This study indicates the value of a systematic assessment of the quality of life of patients with chronic kidney disease as well as the need for assistance for these patients in different areas of their life.
\end{abstract}

\section{Keywords}

Chronic Kidney Disease, Quality of Life, KDQOL 


\section{Introduction}

Chronic kidney disease (CKD) is a major public health problem due to its morbidity, mortality and socio-economic repercussions [1].

In 2015 , up to $5 \%$ of the world's population, or nearly 353 million people, had CKD [1]. Its prevalence in Africa is estimated at 250 per million inhabitants with an incidence of 150 new cases per million inhabitants per year [2]. In Congo, the hospital prevalence of CKD in the nephrology department of the University hospital of Brazzaville was $50.7 \%$ in 2016 [2].

CKD is a major cause of disability and impaired quality of life [3] [4]. In general, an individual with a chronic disease may find it difficult to follow a normal education or training, risk of losing their job, and may be refused a loan, etc. [5]. Several studies have reported a significant deterioration in the quality of life of patients with chronic renal failure in developed countries [6] [7]. Also, the management of CKD is diverse, starting from medicinal means to kidney transplantation. An additional psychological impact can be caused by this care which remains heavy and sometimes inaccessible in our context.

In Africa, few studies have been conducted on assessing the quality of life of patients with CKD. They have reported an alteration in the quality of life of CKD patients [8] [9] [10]. Assessing the quality of life of patients has become a fundamental concept in modern medicine. It is particularly in line with the constant logic of overall improvement in the quality of care [11] [12].

In the Republic of the Congo, few studies have been carried out on CKD with a focus on epidemiological aspects [2] [13]. So far, no study has assessed the quality of life of CKD patients.

In order to improve the overall care of patients with CKD, we conducted this study, objective to assess their quality of life.

\section{Patients and Methods}

\subsection{Study Design and Participants}

We conducted an analytical cross-sectional study July $1^{\text {st }}$ to November $30^{\text {th }}, 2020$, i.e. five months. The study took place in the cities of Brazzaville (department of nephrology of the University Hospital of Brazzaville and 2 private dialysis centers), Pointe-Noire (department of nephrology of Adolphe Cissé Hospital) and Oyo (department of nephrology and dialysis Edith Lucie Edith BONGO ONDIMBA Hospital).

The study population consisted of all patients with CKD followed in different departments of nephrology and dialysis centers; seen in hospital or outpatient.

Were included in our study:

- patients followed for chronic CKD confirmed biologically and morphologically (anemia, hypocalcemia, hyperphosphatemia, kidneys reduced in size and or poorly differentiated);

- patients with a CKD that has been progressing for at least three months;

- patients who have given their informed consent or that of tutor, if applicable, 
in order to participate in the study.

- Not included in the study were:

- CKD patients under the age of 16 ;

- patients with a kidney transplant;

- patients with neuropsychic disorders.

The patients included were subjected to a quadruple investigation: epidemiological, clinical, therapeutic and on quality of life. The data was then collected using a questionnaire completed by a physician using exhaustive sampling.

The data on the QOL were collected by means of the questionnaire "Kidney Disease Quality of Life Short Form" (KDQOL SF) also called "Short Form-36" (SF-36).

The KDQOL-SF is a specific questionnaire widely used in the field of CKD, due to its comprehensiveness compared to other specific measuring instruments for kidney disease; in particular the KDQ and HRQOL which do not take into account the data on sexual function and socio-professional reintegration [14].

The KDQOL, the QOL measurement tool used during this study, has already been validated in a series of patients with CKD and resulted in the version used in the questionnaire used in this study [15].

\subsection{Variables}

The variables studied were:

- Socio-demographic: sex, age (expressed in years), level of education (no schooling, primary, secondary, higher), professional status (student, worker, jobless, retired, unemployed), marital status (single, in relationship, married, divorced, widowed), socio-economic level.

- Clinical variables: comorbidity (hypertension, heart disease, diabetes mellitus, stroke), underlying nephropathy, metabolic disease, neoplasia, habit and lifestyle (alcohol and tobacco consumption), body mass index (BMI), stage of $\mathrm{CKD}$ screening, nurse information consultation, stage of CKD during the study, duration of CKD evolution.

- Therapeutic variable: number of drugs taken per day, therapeutic compliance, psychological consultation and follow-up, extra-renal purification.

- Variables related to quality of life: they were appreciated by the KDQOL elements.

\subsection{Criteria of Judgement}

The KDQOL SF-36 on which the quality of life was assessed had 79 questions divided into 19 items or dimensions. Individual responses to the 79 questions were added up. This addition allowed us to obtain a quantitative score with extremes ranging from 0 to 100 .

Depending on the score, the patients were classified into different groups according to the severity of the QOL alteration: a value less than 25 defined a very severe alteration, a value between 25 and 50 corresponded to a severe alteration, 
a value between 50 and 75 to moderate impairment and a value greater than 75 to slight impairment in quality of life.

\subsection{Statistical Analyses}

Data entry, analysis and processing were done on SPSS 22 statistical software. The qualitative variables were expressed in number and percentage, the quantitative ones as the mean standard deviation or as the median with interquartile range depending on the extent of the distribution. Comparison of proportions and means were done using Pearson's Chi-square test or Student's t-test as appropriated. Quality of life was assessed by the KDQOL SF Scoring Manual. The significance threshold was set at $5 \%$.

\section{Results}

\subsection{Sociodemographic Characteristics}

A total of 91 patients were included in our study. The average age was $51.9 \pm 15$ years (17 to 87 years). The most represented age group was 55 to $75(45.07 \%)$. Men represented $67.03 \%(n=61)$ and women $32.97 \%(n=30)$, i.e. a sex ratio of 2.03 .

During our study $47.25 \%(\mathrm{n}=43)$ patients had a high education level, $45.05 \%$ $(\mathrm{n}=41)$ patients had a secondary education level and $7.69 \%(\mathrm{n}=7)$ patients had elementary education level.

The general population of our study was made up of $35.16 \%(n=32)$ workers; $32.97 \%(n=30)$ retired; $30.77 \%(n=28)$ patients were jobless and unemployed; $1.1 \%(\mathrm{n}=1)$ patient was a student.

The most represented socio-economic group was the middle-income accounting for $60.44 \%(n=55)$ followed by low-income group $29.67 \%(n=27)$ and high income $9.89 \%(n=9)$.

Out of 91 patients included, $32(32.35 \%)$ were married, 33 (36.67\%) were in a relationship, 18 (20\%) were single and 7 (7.69.2\%) were widowed.

\subsection{Clinical Features}

\subsubsection{CKD Discovery Stage}

In $53.85 \%$ of cases $(n=49)$ patients were either diagnosed with CKD at stage $3 b$, 16 patients $(17.58 \%)$ were at stage $3 \mathrm{a}, 17$ patients $(18.68 \%)$ were at stage 4 of CKD, 4 patients (4.4\%) were between stage 2 and final stage. Only one patient in our study was at stage 1 of CKD.

The distribution of patients according to the stage of CKD screening is shown in Table 1.

\subsubsection{Stage of CKD at Time of Study}

At the time of the survey, most patients were divided between stage 4 and 5 of the progression of CKD with $38.43 \%$ at the end stage followed by $35.16 \%$ at stage $3 \mathrm{~b}$. 
Table 1. Distribution of patients according to stage of CKD screening.

\begin{tabular}{ccc}
\hline CKD stages & $\mathbf{n}$ & $\%$ \\
\hline Stage 1 & 1 & 1.1 \\
Stage 2 & 4 & 4.4 \\
Stage 3a & 16 & 17.58 \\
Stage 3b & 49 & 53.85 \\
Stage 4 & 17 & 18.68 \\
Stage 5 & 4 & 4.4 \\
Total & 91 & 100 \\
\hline
\end{tabular}

Table 2. Distribution of patients according to stage of CKD at the time of the study.

\begin{tabular}{ccc}
\hline CKD stages & $\mathbf{n}$ & $\%$ \\
\hline Stage 2 & 2 & 2.20 \\
Stage 3a & 15 & 16.48 \\
Stage 3b & 32 & 35.16 \\
Stage 4 & 7 & 7.69 \\
Stage 5 & 35 & 38.43 \\
Total & 91 & 100 \\
\hline
\end{tabular}

The distribution of patients according to the stage of CKD at the time of the survey is shown in Table 2.

\subsubsection{Duration of CKD Evolution}

The average duration of progression of CKD was $15 \pm 12$ months ( 3 to 72). This evolutionary time was less than 5 years for 65 patients (54.6\%) and more than 10 years for $10(8.4 \%)$ patients.

\subsubsection{Medical History of Patients}

High blood pressure and diabetes mellitus were found in $90.11 \%$ and $30.77 \%$ of patients, respectively.

Among the patients in our study $69(75.82 \%)$ had ever had to consume alcohol. Among them are 50 (72.46\%) who had no longer consumed alcohol during the last 12 months and 19 (27.54\% of patients who had already consumed alcohol, i.e. $20.87 \%$ of our population general had not stopped drinking alcohol.

Among the patients included in our study 18 (19.78\%) had already consumed tobacco. Among them are $14(77.78 \%)$ who had not used tobacco in the past 12 months and 4 (22.22\% or $4.39 \%$ of our general population) had not stopped alcohol.

The average body mass index (BMI) was $25 \pm 3.3 \mathrm{~kg} / \mathrm{m}^{2}$ (18 to $\left.32 \mathrm{~kg} / \mathrm{m}^{2}\right) ; 3.3 \%$ or 03 patients had a BMI less than $18.5 \mathrm{~kg} / \mathrm{m}^{2}$ and 41 (45.05\%) patients had a normal BMI between 18.5 and $25 \mathrm{~kg} / \mathrm{m}^{2}$. A proportion of $38.46 \%(\mathrm{n}=35)$ of patients was overweight and 12 patients (13.19\%) were obese. 


\subsection{Therapeutic Characteristics}

\subsubsection{Extra-Renal Purification}

The thirty-six patients $(39.56 \%)$ with end stage renal disease received hemodialysis while the remaining 55 (60.44\%) patients did not have hemodialysis.

\subsubsection{Number of Medication per Day}

Patients had an average of 4.6 drugs to take per day with extremes of 2 to 8 .

\subsubsection{Therapeutic Adherence}

Only 39 patients in our study (42.86\%) reported being compliant with the prescribed treatment. The $52(57.14 \%)$ other patients reported poor treatment adherence.

\subsubsection{Dietitian Consultation}

The patients who benefited from a consultation and support from the dietitian were $19(20.88 \%)$. The majority of patients, $79.12 \%(n=72)$, had not benefited from it.

\subsubsection{Consultation and Psychological Follow-Up}

None of the patients included in our study had received psychological follow-up.

\subsection{Quality of Life}

Quality of Life Dimensions According to KDQOL-SF36

\section{- General quality of life}

The patients with a quality of life score in general between 50\% and 75\% (moderate) were 43 in number, $47.25 \%$ followed by $43.96 \%$ with a severe alteration in QOL. A small proportion of $8.79 \%$ had a slight alteration in general QOL.

\section{- Generic quality of life sub-scores}

The dimension of limitation of physical activity was the most affected dimension in our study accounting for 61 (67.03\%) of very severe affected cases. Table 3 shows the distribution of patients according to the quality of life impairment sections of the various dimensions of the KDC.

\section{Discussion}

\subsection{Sociodemographic Aspects}

\subsubsection{Age}

The mean age in our study was $51.9 \pm 15$ years with extremes of 17 to 87 years. The most represented age group was that of patients aged 50 to 59 (45.05\%). These results were similar to those reported in the African literature. Ogheneovo et al. in Nigeria, Yaya et al. in Senegal, Zouari et al. in Tunisia and Duarte et al. in Brazil reported an average age close to that of our study, i.e. respectively 51.25 years, 50.25 years, 49.17 years and 49 years old [16] [17] [18] [19].

\subsubsection{Sex}

The male predominance seems to be most often found in the literature. Our study reported a large male predominance with a sex ratio established at 2.03. 
Table 3. Distribution of CKD patients according to standardized scores for the dimensions of quality of life according to SF-36 questionnaire.

\begin{tabular}{ccccc}
\hline QOL Alteration & $\begin{array}{c}\text { Very severe } \\
\mathbf{n}(\%)\end{array}$ & $\begin{array}{c}\text { Severe } \\
\mathbf{n}(\%)\end{array}$ & $\begin{array}{c}\text { Moderate } \\
\mathbf{n}(\%)\end{array}$ & $\begin{array}{c}\text { Slight } \\
\mathbf{n}(\%)\end{array}$ \\
\hline Physical functioning & $15(16.43 \%)$ & $27(26.67 \%)$ & $23(25.27 \%)$ & $26(28.57 \%)$ \\
Limitations of physical activities & $61(67.03 \%)$ & $4(4.39 \%)$ & $7(7.69 \%)$ & $19(20.87 \%)$ \\
Bodily pain & $18(19.78 \%)$ & $17(18.68 \%)$ & $24(26.37 \%)$ & $32(36.16 \%)$ \\
Health perceptions & $9(9.89 \%)$ & $49(53.85 \%)$ & $31(34.06 \%)$ & $2(2.19 \%)$ \\
Mental health & $4(4.39 \%)$ & $26(28.57 \%)$ & $41(45.05 \%)$ & $19(20.87 \%)$ \\
Mental health limitation & $25(27.47 \%)$ & $12(13.18 \%)$ & $6(6.59 \%)$ & $48(52.74)$ \\
social role functioning & $6(6.59 \%)$ & $32(35.16 \%)$ & $27(29.67 \%)$ & $26(28.57 \%)$ \\
Vitality & $21(23.07 \%)$ & $32(35.16 \%)$ & $27(29.67 \%)$ & $11(6.59 \%)$ \\
Perceived health evolution & $17(18.68 \%)$ & $40(43.95 \%)$ & $21(23.07 \%)$ & $13(14.28 \%)$ \\
PCS & $14(15.38 \%)$ & $49(53.85 \%)$ & $16(17.58 \%)$ & $12(13.19 \%)$ \\
MCS & $10(10.99 \%)$ & $25(27.47 \%)$ & $37(40.66 \%)$ & $19(20.88 \%)$ \\
\hline
\end{tabular}

This predominance concerns almost all age groups. It was also observed in Mali and Tunisia with a sex ratio of 2 and 1.73 respectively [18] [20]. Studies conducted in Malawi (59.1\%) [21], Ghana (58.4\%) [22] have shown a lower male predominance.

\subsubsection{Education}

A high proportion of the patients in our study, i.e. 45.05\%, had a secondary education level. These results were similar to studies carried out in Kenya [23], Mali [20] and Ghana with 45\%, 40\% and 60\% respectively. Unlike Zouari [18] et al. in Tunisia [17] as well as Yaya et al. in Senegal who respectively had $40.8 \%$ and $31.25 \%$ out of school, all those who responded favorably to our study were in school. This can be explained by the existence of a fairly developed informal education system in these countries which was not taken into account in their studies and also by the free education for several years in Congo.

\subsubsection{Professional Status}

A cumulative $62.97 \%$ of the patients in our study were inactive, which is comparable to the results of studies conducted in Mali [20] with $63.27 \%$ of inactive. In Kenya $75 \%$ of patients were inactive. This study was carried out in patients with end-stage chronic renal failure on chronic hemodialysis [23], which explains the differences observed with the other studies.

\subsubsection{Socio-Economic Level}

A proportion of $60.44 \%$ of our patients had an average socio-economic level which can be explained by the Congolese minimum wage which is 90,000 FCFA (180 USD). 


\subsubsection{Marital Status}

The vast majority of patients in our study, ie $72.1 \%$, were married or living in a conjugal relationship. Similar results were obtained in Ghana [22], Mali [20] and Senegal [24] with $67.8 \%, 70 \%$ and $79.7 \%$ respectively.

\subsection{Clinical Features}

\subsubsection{CKD Stage at Diagnosis}

Patients in our study were on average stage $3 \mathrm{~b}$ of chronic kidney disease with $53.85 \%$ at this stage at the time of diagnosis. This can be explained by the delay in consultation with doctors for patients without comorbidities or by inadequate follow-up and monitoring of patients with comorbidities such as hypertension and diabetes mellitus.

\subsubsection{Duration of CDK}

The short duration of CKD on average 15 months in the patients in our study may be a reflection of the significant mortality of patients with chronic renal failure.

\subsection{Therapeutic Features}

\subsubsection{Extra-Renal Purification}

During our study, 36 patients or $39.56 \%$ were at the end stage of CKD versus $18.84 \%$ in Carolina et al. in Brazil in 2011 [25]. This can be explained by the delay in diagnosis, the difficulties related to treatment compliance.

\subsubsection{Therapeutic Adherence}

Only $42.86 \%$, or 39 patients in our study, were compliant with the therapy prescribed by the doctor. This could be explained by the cost of treating CKD, which is very high and not very compatible with the overall socio-economic level of our patients. These results are similar to those of the literature reported in China [16].

\subsubsection{Dietitian Consultation}

The lack of a dietitian in most of our nephrology departments and dialysis centers may be one of the reasons why only $20.88 \%$ of our patients had received a consultation with a nutritionist. This important phase of their care was often taken care of by the attending physician.

\subsection{Quality of Life}

\section{Standardized KDQOL Dimension Scores}

Quality of life is the perception of satisfaction perceived by patients with their state of health. In the literature, the self-assessed quality of life of patients is altered during CKD regardless of the tool used, as the results of series of different authors seem to confirm. In fact, Kamal et al. in Egypt and Duarte et al. in Brazil using the KDQOL questionnaire and the health-related quality of life (HRQOL) questionnaire respectively had concluded that the quality of CKD patients in 
their series was altered respectively [19] [26].

The dimension of limitation of physical activity, professional status and the burden of disease were the dimensions most affected as in the data in the literature [17] [18] [21] [24].

The results of our study were superimposable to those reported by Masina et al. in Malawi, Yaya et al. in Senegal in 2016 and 2019 [17] [24].

The quality of life varies depending on the cultures and the adaptation or validation of the tool used. Zouari et al. in Tunisia [18] reported greater alteration in QOL than those in our study in the dimensions of SF-36, but also less good QOL than those obtained in Malawi and Senegal (except for the physical pain dimension).

This difference could lie in the fact that their study only took into account hemodialysis patients and mostly over 60 years of age. Overall, CKD appeared to affect the quality of life of the patients in our study. The impact of CKD on quality of life was similar to that of CKD patients in the series by Massina et al. in Malawi [21].

\subsection{Limitations of the Study}

Our study presented several limitations. The first was the small sample size, which obviously reduces the power of the observations and makes it difficult to extrapolate the results to the general population. The second limitation was related to the recruitment of patients in a hospital environment, an environment in which advanced forms are more frequent. Finally, KDQOL was used without prior validation and adaptation in the Congolese environment. However, the questions were asked in national languages for patients with difficulty understanding French.

Despite these limitations, we obtained results that can be discussed with the data in the literature in order to enhance this work.

\section{Conclusion}

This study indicates the value of a systematic assessment of the quality of life of patients with CKD as well as the need for assistance for these patients in different areas of their life.

\section{Conflicts of Interest}

The authors declare no conflicts of interest regarding the publication of this paper.

\section{References}

[1] Ramilitiana, B., Ranivoharisoa, E.M., Dodo, M., Razafimandimby, E. and Randriamarotia, W.F. (2016) Une étude rétrospective sur l'incidence de l'insuffisance rénale chronique dans le service de Médecine Interne Néphrologie du Centre Hospitalier d'Antananarivo. The Pan African Medical Journal, 23, Article No. 141.

[2] Eyeni Sinomono, D.T., Gassongo Koumou, G.C. and Loumingou, R. (2017) Profil 
épidémiologique de l'insuffisance rénale chronique au CHU de Brazzaville en 2016. Néphrologie \& Thérapeutique, 13, 396. https://doi.org/10.1016/j.nephro.2017.08.302

[3] Baudelot, C., Caillé, Y. and Mercier, S. (2015) Activité professionnelle et ressources des personnes en insuffisance rénale chronique terminale en France en 2011. Néphrologie \& Thérapeutique, 11, 267-268. https://doi.org/10.1016/j.nephro.2015.07.026

[4] Augusto, R.C., Krzesinki, J.M., Warling, X., Smelten, N. and Etienne, A.M. (2011) Intérêt des interventions psychologiques en dialyse: étude exploratoire. Néphrologie \& Thérapeutique, 7, 211-218. https://doi.org/10.1016/j.nephro.2010.12.006

[5] Baumann, C. and Briançon, S. (2010) Maladie chronique et qualité de vie: Enjeux, définition et mesure. Actualité et Dossier en Santé Publique, 72, 19-21.

[6] Beauger, D., Gentile, S., Jacquelinet, C., Dussol, B. and Briançon, S. (2015) Comparaison de deux enquêtes nationales sur la qualité de vie des patients atteints d'insuffisance rénale chronique terminale entre 2005-2007 et 2011: Des indicateurs sensiblement en baisse. Néphrologie \& Thérapeutique, 11, 88-96.

https://doi.org/10.1016/j.nephro.2014.10.003

[7] Deloumeaux, J., Samut, G., Rochemont, D., Merault, H., Dufresne, R., Galantine, V., et al. (2018) Contexte initial de prise en charge et qualité de vie à 3 mois des patients dialysés pour insuffisance rénale chronique terminale dans deux départements français d'Amérique. Néphrologie \& Thérapeutique, 14, 467-473.

https://doi.org/10.1016/j.nephro.2017.12.002

[8] Chrifi Alaoui, A., Touti, W., Al Borgi, Y., Sqalli Houssaini, T. and El Rhazi, K. (2021) Comparison of Quality of Life in End-Stage Renal Disease Patients Undergoing Hemodialysis and Peritoneal Dialysis in a Moroccan City. In: Agarwal, S., Ed., Seminars in Dialysis, Wiley Periodicals, Hoboken, 1-8.

https://doi.org/10.1111/sdi.13034

[9] Bagasha, P., Namukwaya, E., Leng, M., Kalyesubula, R., Mutebi, E., Naitala, R., et al. (2021) Comparison of the Health-Related Quality of Life of End Stage Kidney Disease Patients on Hemodialysis and Non-Hemodialysis Management in Uganda. BMC Palliative Care, 20, Article No. 52. https://doi.org/10.1186/s12904-021-00743-0

[10] Tannor, E.K., Archer, E., Kapembwa, K., van Schalkwyk, S.C. and Davids, M.R. (2017) Quality of Life in Patients on Chronic Dialysis in South Africa: A Comparative Mixed Methods Study. BMC Nephrology, 18, Article No. 4.

https://doi.org/10.1186/s12882-016-0425-1

[11] Albert, S.M. (1998) Defining and Measuring Quality of Life in Medicine. JAMA, 279, 429-431. https://doi.org/10.1001/jama.279.6.429

[12] Taoues, C. and Nouara, K. (2015) L'insuffisance Rénale Chronique Terminale en Algérie: Aspects épidémiologiques et économiques. Les Cahiers du Cread, 112, 113-135.

[13] Gandzali Ngabe, P.E., Loumingou, R., Yattara, R., Okouango Imangue, G.N. and Moukassa, D. (2020) Profil épidémiologique des patients en hémodialyse à l'hôpital général Edith Lucie Bongo Ondimba. Mali Médical, 35, 62-64.

[14] Valderrábano, F., Jofre, R. and López-Gómez, J. (2001) Quality of Life in End-Stage Renal Disease Patients. American Journal of Kidney Disease, 38, 443-464. https://doi.org/10.1053/ajkd.2001.26824

[15] Hays, R.D., Kallich, J.D., Mapes, D.L., Coons, S.J. and Carter, W.B. (1994) Development of the Kidney Disease Quality of Life (KDQOL) Instrument. Quality of Life Research, 3, 329-338. https://doi.org/10.1007/BF00451725

[16] Aghoja, O.C., Akonoghrere, R.O., Odili, V.U. and Ajagbe, O. (2020) Quality of Life 
of Patients with Chronic Kidney Disease in Two Health Facilities in Delta State, Nigeria. Tropical Journal of Pharmaceutical Research, 19, 1759-1765.

https://doi.org/10.4314/tjpr.v19i8.27

[17] Yaya, K., Moustapha, C.M., Mohamed, S.S., Tall, L.A., Maria, F., Christian, H., et al. (2016) Quality of Life of Patients on Peritoneal Dialysis in Dakar: A Senegalese Single Centre Experience. Open Journal of Nephrology, 6, 37-42. https://doi.org/10.4236/ojneph.2016.62005

[18] Zouari, L., Omri, S., Turki, S., Maalej, M., Charfi, N., Ben Thabet, J., Mahfoudh, H., Hachicha, J. and Maalejâle, M. (2016) Qualité de vie des patients hémodialysés chroniques: Environ 71 cas. La Tunisie Medicale, 94, 40-45.

[19] Duarte, P.S., Ciconelli, R.M. and Sesso, R. (2005) Cultural Adaptation and Validation of the "Kidney Disease and Quality of Life-Short Form (KDQOL-SF 1.3)" in Brazil. Brazilian Journal of Medical and Biological Research, 38, 261-270. https://doi.org/10.1590/S0100-879X2005000200015

[20] Diallo, D., Fongoro, S., Doumbia, S., Maïga, H. and Arama, C. (2011) Study of the Quality of Life of Hemodialysis Patients at the University Hospital of Point G (CHU) in Bamako-The Study of 30 Cases. Mali Médical, 26, 16-20.

[21] Masina, T., Chimera, B., Kamponda, M. and Dreyer, G. (2016) Health Related Quality of Life in Patients with End Stage Kidney Disease Treated with Haemodialysis in Malawi: A Cross Sectional Study. BMC Nephrology, 17, Article No. 61. https://doi.org/10.1186/s12882-016-0292-9

[22] Tannor, E.K., Norman, B.R., Adusei, K.K., Sarfo, F.S., Davids, M.R. and Bedu-Addo, G. (2019) Quality of Life among Patients with Moderate to Advanced Chronic Kidney Disease in Ghana-A Single Centre Study. BMC Nephrology, 20, Article No. 122. https://doi.org/10.1186/s12882-019-1316-Z

[23] Kamau, E., Kayima, J. and Otieno, C.F. (2014) The Determinants of Health-Related Quality of Life of Patients on Maintenance Haemodialysis at Kenyatta National Hospital, Kenya. East African Medical Journal, 91, 368-374.

[24] Yaya, K., Biao, H.B., Moustapha, F., Ibrahim, H., Tall, L.A., et al. (2019) Quality of Life in Chronic Hemodialysed Patients: Observational Study in Three Hemodialysis Units in Semi-Urban Areas of Senegal (West Africa). Journal of Clinical Nephrology and Renal Care, 5, Article No. 45. https://doi.org/10.23937/2572-3286.1510045

[25] Cruz, M.C., Andrade, C., Urrutia, M., Draibe, S., Nogueira-Martins, L.A. and Sesso Rde, C. (2011) Quality of Life in Patients with Chronic Kidney Disease. Clinics, 66, 991-995. https://doi.org/10.1590/S1807-59322011000600012

[26] Kamal, N.N., Kamel, E.G., Eldessouki, K.H., et al. (2013) Qualité de vie liée à la santé chez les patients hémodialysés à l'hôpital universitaire d'El-Minia, Égypte. Journal of Public Health, 21, 193-200. https://doi.org/10.1007/s10389-012-0538-3 